\title{
Recognition, diagnosis, and treatment of cognitive and psychiatric disorders in patients with COPD
}

\author{
This article was published in the following Dove Press journal: \\ International Journal of COPD \\ 16 February 2017 \\ Number of times this article has been viewed
}

\author{
Daniel R Ouellette' \\ Kim L Lavoie ${ }^{2}$ \\ 'Department of Pulmonary and \\ Critical Care Medicine, Henry \\ Ford Hospital, Detroit, MI, USA; \\ ${ }^{2}$ Montreal Behavioral Medicine Center \\ (MBMC), Research Center, Integrated \\ University Health and Social Services \\ Center - Sacred Heart Hospital of \\ Montreal, Montreal, QC, Canada
}

\begin{abstract}
COPD is highly prevalent and associated with substantial morbidity and mortality. Clinicians have long been aware that patients with COPD have problems with cognition and are susceptible to mood (depression) and anxiety disorders. With the increasing awareness of COPD as a multisystem disorder, many studies have evaluated the prevalence of neuropsychiatric conditions in patients with COPD. This review presents evidence regarding the prevalence of neuropsychiatric conditions (cognitive disorders/impairment, depression/anxiety) in COPD, their risk factors, and their impact on relevant outcomes. It also discusses both assessment and treatment of neuropsychiatric conditions and makes recommendations for improved screening and treatment. The findings suggest that clinicians caring for patients with COPD must become familiar with diagnosing these comorbid conditions and that future treatment has the potential to impact these patients and thereby improve COPD outcomes.
\end{abstract}

Keywords: COPD, cognitive impairment, mood disorders, anxiety disorders, hypoxemia, pulmonary rehabilitation

\section{Introduction}

COPD is a highly prevalent condition with substantial attributable morbidity and mortality. In the US, it is estimated that 24 million adults have COPD, ${ }^{1-3}$ whereas the Canadian Health Measures Survey reports that $\sim 1$ million Canadians may have this condition. ${ }^{4}$ COPD is the third leading cause of death in the US ${ }^{5,6}$ and the fourth leading cause of death in Canada. ${ }^{4}$ In developed nations, it is characterized by dyspnea and poorly reversible airflow obstruction caused mostly by cigarette smoking. ${ }^{7}$ Once thought of as a condition that involved only lungs, COPD is increasingly being associated with comorbidities that have an incidence greater than the general population. ${ }^{8,9}$ Patients with COPD are more likely to have coronary artery disease, ${ }^{8,10}$ lung cancer, ${ }^{11,12}$ metabolic syndrome, ${ }^{13,14}$ osteoporosis, ${ }^{15,16}$ diabetes mellitus, ${ }^{8,17}$ and hypertension ${ }^{8,18}$ than persons without COPD, resulting in some suggesting COPD be considered a multisystem inflammatory disorder rather than a condition confined to the lungs. ${ }^{9,19}$

Clinicians have long been aware that patients with COPD have problems with cognition and are susceptible to mood (depression) and anxiety disorders. ${ }^{20}$ However, some clinicians may attribute these ailments to the effects of aging and the impact of COPD on patients' quality of life. With the increasing awareness of COPD as a multisystem disorder and the concern that patients with COPD have underlying pathophysiologic anomalies that may predispose them to other associated conditions, ${ }^{9}$ many recent studies have investigated whether the prevalence of neuropsychiatric 
conditions is increased in these patients, ${ }^{21}$ and whether links exist between neuropsychiatric conditions and COPD severity and outcomes. ${ }^{20}$ This review summarizes the available information regarding the association of COPD with cognitive and psychiatric disorders.

\section{Classification and definitions}

Patients with a cognitive disorder have a mental health problem that affects learning, memory, perception, and/or problem solving. ${ }^{22}$ Most of these disorders feature damage to areas of the brain concerned with memory. ${ }^{23,24}$ The main cognitive disorders characterized by the Diagnostic and Statistical Manual of Mental Disorders (DSM) ${ }^{25}$ are delirium, ${ }^{23}$ dementia, ${ }^{24}$ amnesia, ${ }^{26}$ and mild cognitive impairment (MCI) ${ }^{27}$ (Table 1).

Cognitive disorders range from mild to severe. MCI is defined as impaired cognitive functioning that is greater than expected for a patient's age and education level but not severe enough to be considered as dementia or interfere with normal daily activities. ${ }^{28,29}$ Patients with MCI have problems with memory and word finding ${ }^{27}$ and are at high risk for developing severe cognitive impairment, that is, dementia. ${ }^{30,31}$ Dementia is more severe than MCI, involves an additional cognitive domain other than memory, and interferes with a person's ability to carry out routine daily activities. ${ }^{27}$

Patients with a psychiatric disorder are commonly described as having mood (depression) or anxiety disorders. Mood disorders are characterized by persistent ( $>2$ weeks) negative mood (particularly sadness, hopelessness, and pessimism) accompanied by decreased interest or pleasure in engaging in otherwise pleasurable activities. ${ }^{25}$ Mood disorders are also associated with sleep and appetite disturbances, significant weight gain or loss $( \pm 10 \%)$, fatigue, decreased libido, and psychomotor agitation or retardation.

Anxiety disorders are characterized by chronic ( $>6$ months) symptoms of fear, anxiety, and worry that typically lead to persistent avoidance of the feared object (which differs according to the disorder [Table 1]). ${ }^{25}$ Somatic symptoms such as sleep disturbances, fatigue, palpitations, breathlessness, and dizziness are also associated with anxiety disorders, but symptoms must be severe enough to cause functional impairment in occupational or social activities for a person to be diagnosed with an anxiety disorder.

Patients with COPD are predisposed to both cognitive and psychiatric disorders. ${ }^{9}$ The available information regarding links between these disorders and COPD severity and outcomes is summarized in the following sections.

\section{Cognitive disorders Occurrence of cognitive disorders in COPD}

\section{Prevalence}

Most of the studies demonstrate an increased occurrence of cognitive disorders in patients with COPD. ${ }^{21}$ AntonelliIncalzi et al described a high prevalence of cognitive dysfunction by a mini-mental state examination (MMSE) among $32.8 \%$ of 149 patients with severe COPD, albeit in a small patient cohort with no comparator group included. ${ }^{32}$ These authors previously characterized the neuropsychiatric profile of a small cohort of patients with hypoxic-hypercapnic COPD $(n=36)$ by comparing their cognitive domain test scores to a control group (healthy adults, healthy elderly adults,

Table I Classification of disorders of cognition, mood, and anxiety relevant to COPD

\begin{tabular}{|c|c|c|}
\hline Cognitive disorders & Mood disorders & Anxiety disorders \\
\hline Delirium & $\begin{array}{l}\text { Major depressive disorder (depressed mood } \\
\text { and loss of interest or pleasure in daily } \\
\text { activities }+3 \text { additional somatic or psychological } \\
\text { symptoms on most days for } 2 \text { weeks or longer) }\end{array}$ & $\begin{array}{l}\text { Generalized anxiety disorder } \\
\text { (fear: uncertainty) }\end{array}$ \\
\hline Dementia & $\begin{array}{l}\text { Bipolar disorder (manic episodes intermittent } \\
\text { with depressive episodes) }\end{array}$ & $\begin{array}{l}\text { Panic disorder (fear: somatic and } \\
\text { psychological symptoms of anxiety) }\end{array}$ \\
\hline Amnesia & $\begin{array}{l}\text { Dysthymia (chronic depression intermittent } \\
\text { with stable mood for no more than } 2 \text { months } \\
\text { at a time) }\end{array}$ & $\begin{array}{l}\text { Obsessive-compulsive disorder } \\
\text { (fear: multiple; commonly contamination, } \\
\text { committing violence, forgetting) }\end{array}$ \\
\hline Mild cognitive impairment & & $\begin{array}{l}\text { Social anxiety disorder (fear: social criticism, } \\
\text { judgment, and rejection) } \\
\text { Post-traumatic stress disorder } \\
\text { (fear: re-exposure to the traumatic event) } \\
\text { Specific phobia (fear: multiple depending } \\
\text { on phobia; commonly animals, heights, } \\
\text { needles/blood) }\end{array}$ \\
\hline
\end{tabular}


Alzheimer patients, and multi-infarct dementia patients). Discriminant analysis of the test scores classified the COPD patients as cognitively impaired (49\%), healthy elderly adults (15\%), healthy adults (12\%), adults with Alzheimer-type dementia (12\%), or adults with multi-infarct dementia (12\%). The COPD patients classified as cognitively impaired had a specific pattern of findings characterized by deficits in verbal skills and verbal memory but preserved visual attention.

In a large US longitudinal health survey, Martinez et al reported that $9.5 \%$ of 17,535 participants ( $\geq 53$ years of age) reported COPD, and $17.5 \%$ of those had MCI, which was significantly higher compared with all respondents (13.1\%, $P=0.001) .{ }^{33}$ They estimated that 1.3 million US adults have both COPD and cognitive impairment. Villeneuve et al identified MCI in $36 \%$ of COPD patients $(n=45)$ compared with $12 \%$ in the healthy controls $(n=50) .{ }^{34}$ Other studies have also confirmed a high prevalence of cognitive impairment in patients with COPD. ${ }^{35,36}$ Also, dementia is a frequent diagnosis in patients with COPD. Studying a Taiwan national health database, Liao et al found that the hazard ratio for the development of dementia in COPD patients was 1.74 compared with patients without COPD after adjusting for age, gender, and comorbidities. ${ }^{37}$ In contrast, a few studies suggest that the prevalence of cognitive deficits may not be higher in patients with $\mathrm{COPD}^{38-40}$ or that cognitive deficits are confined to those patients with COPD who have chronic hypoxemia. ${ }^{39}$ However, others have found that even nonhypoxemic COPD patients do have cognitive deficits. ${ }^{41}$

\section{Risk factors}

Multiple risk factors are associated with the development of cognitive impairment in COPD patients. Using data from the Cardiovascular Risk Factors, Aging and Dementia study $(n=2,000)$, Rusanen et al found that midlife COPD conferred a 1.85-fold risk of cognitive impairment later in life (after controlling for other measured factors). ${ }^{42}$ Similarly, COPD was significantly associated with the risk of developing cognitive impairment in the Mayo Clinic Study on Aging (hazard ratio $1.83 ; \mathrm{n}=1,425) .{ }^{43}$ In addition, Tulek et al examined cognition in mostly male patients with COPD $(n=119)$ and determined that the frequency of COPD exacerbations was inversely associated with cognition, potentially implicating exacerbation severity in the development of cognitive impairment. ${ }^{44}$ Etnier et al found that age and aerobic fitness were also associated with cognitive performance in COPD patients, ${ }^{45}$ whereas another study observed that very elderly ( $\geq 75$ years of age) men with COPD have a particularly rapid decline in cognitive function, ${ }^{46}$ suggesting that COPD is a significant risk factor for cognitive decline in older patients. In general, the risk factors for the development of cognitive impairment in COPD may be associated with chronic hypoxia-hypercapnia, which has been reported to correlate with cognitive deficits in patients with COPD. ${ }^{47,48}$

\section{Assessment}

The use of multiple diagnostic tests may improve the detection of cognitive deficits. Antonelli-Incalzi et al demonstrated that the combination of the MMSE with the instrumental activities of daily living tool had better diagnostic accuracy for cognitive deficits in COPD than either instrument alone. ${ }^{49}$ Other diagnostic tests that have demonstrated utility include the Montreal Cognitive Assessment test, ${ }^{50}$ the Trail Making Test, tactual performance tests, the Wechsler Adult Intelligence Scale, immediate and delayed verbal and nonverbal memory tests, ${ }^{51,52}$ and the Alzheimer's Disease Assessment Scale-Cognitive subscale. ${ }^{53}$ Furthermore, electroencephalography utilizing both auditory and visual P300-evoked responses has revealed that progressive impairment of the auditory (but not visual) P300 reaction time occurs with increasing severity of COPD..$^{54,55}$

\section{Mechanisms linking cognitive impairment to COPD}

Patients with COPD have cognitive deficits that seem to correlate with the degree of hypoxemia. Abnormalities are not limited to neuropsychological testing, as these patients have structural and functional brain abnormalities as well. Postulated mechanisms for cognitive deficits and structural and functional brain abnormalities in COPD may involve hypoxemia, ${ }^{47,48}$ hypercapnia, ${ }^{48,56}$ cigarette smoking, ${ }^{57}$ inflammation, ${ }^{58}$ vascular disease, ${ }^{8,59}$ sleep disturbance, ${ }^{60}$ lack of activity, ${ }^{45}$ and depression ${ }^{61}$ (Figure 1), though it

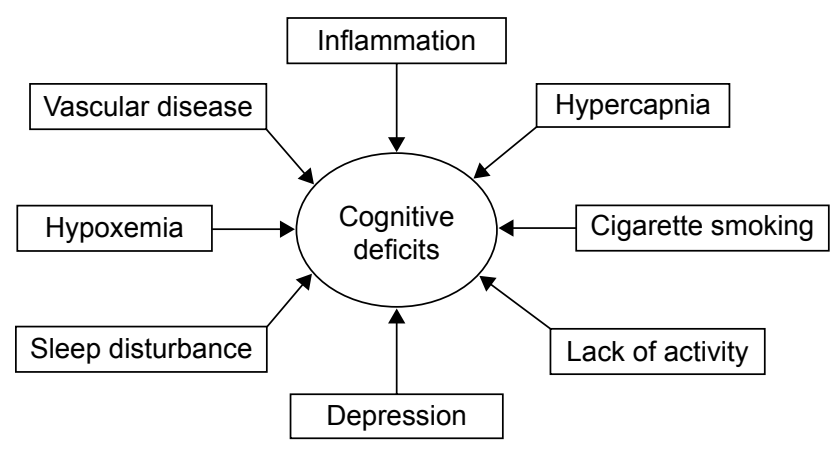

Figure I Contributing factors to cognitive deficits in patients with COPD. ${ }^{a}$ Note: ${ }^{a}$ Cause-effect relationships between the contributing factors, cognitive defects, and COPD are not implied. 
is unlikely that any one of these mechanisms is sufficient to explain cognitive impairment in COPD. For example, prevalence of depression in COPD ranges from 10\%-79\% but accounts for only $1 \%-2 \%$ of the variance in cognition in these patients. ${ }^{20}$ In addition, COPD patients with coexistent vascular disease ${ }^{62}$ have a different pattern of cognitive dysfunction compared with those with vascular dementia, ${ }^{56}$ and memory has been shown to be worse in subjects with cerebrovascular disease than in those with COPD. ${ }^{38}$ Thus, although a number of mechanisms seem to be associated with cognitive impairment, it remains unproven that these mechanisms entirely account for the cognitive deficits observed in patients with COPD.

Many studies support the hypothesis that cognitive deficits in COPD are the result of hypoxemia. A study in patients with asthma or COPD $(n=40)$ demonstrated a direct correlation between low oxygen saturation and poor performance on certain tests of cognition. ${ }^{63}$ In a larger controlled study $(n=1,202)$ of patients with COPD, Thakur et al found an association between low oxygen saturation and cognitive impairment as determined by the MMSE (odds ratio [OR] 5.45 for patients with oxygen saturation $<88 \%$ ), as well as a reduced risk for cognitive impairment in patients receiving supplemental oxygen (OR 0.14). ${ }^{64}$ These studies, as well as those previously cited, ${ }^{32,56}$ suggest a relationship between hypoxemia and cognitive deficits in patients with COPD.

Data from imaging studies also suggest a relationship between hypoxemia and cognitive deficits in patients with COPD. A single-photon emission computed tomography (SPECT) study showed that patients with hypoxemic COPD had evidence of hypoperfusion in the anterior cortical and subcortical regions of the brain compared with healthy control subjects and COPD patients without hypoxemia. ${ }^{65}$ Furthermore, the degree of hypoperfusion correlated with the degree of neuropsychological dysfunction. A similar SPECT study demonstrated decreased cerebral perfusion, with the degree of decrement correlating with the degree of cognitive deficits. ${ }^{47}$ Moreover, although all COPD patients had impaired verbal memory, hypoxemic COPD patients had lower recall and attention scores compared to nonhypoxemic patients.

$\mathrm{Li}$ and Fei used magnetic resonance imaging (MRI) to assess hippocampal volume, an indicator of cognitive performance. ${ }^{6}$ COPD patients had smaller hippocampal volume than normal controls. However, the hippocampal volume was not different between patients with mild to moderate COPD and those with severe COPD. Dodd et al extended these results in nonhypoxemic COPD patients using advanced MRI techniques and identified substantial reductions in both white matter integrity and gray matter functional activation, which corresponded to cognitive dysfunction. ${ }^{67}$

\section{Clinical outcomes in patients with COPD and cognitive deficits}

Patients with COPD who have cognitive deficits suffer from adverse health care outcomes. Martinez et al studied the development of disability in a large COPD population. ${ }^{33}$ The data, captured in the Health and Retirement Study, defined disability as dependency in one or more activities of daily living. Martinez et al reported that prevalent disability was present at baseline in $12.8 \%$ of the COPD population compared with $5.2 \%$ in the non-COPD population $(P<0.001)$ and that incident disability during 2 years of follow-up was $9.2 \%$ in the COPD population compared with $4.0 \%$ in the non-COPD population $(P<0.001)$. Of note, the presence of cognitive impairment in the patients with COPD had an additive effect on prevalent and incident disability. Together, these data suggest that COPD and cognitive impairment increase the risk of disability.

In patients hospitalized with an acute COPD exacerbation, impaired cognitive function is associated with worse health status and longer hospital length of stay. ${ }^{68}$ In addition, patients with cognitive decline and COPD may be at greater risk of hospitalization for respiratory problems. The Cardiovascular Health Study involved 3,093 patients $>65$ years of age; 431 had COPD. ${ }^{69}$ Patients who had both COPD and cognitive decline had the highest rate of hospitalization for respiratory problems, the highest all-cause hospitalization rate, and the highest death rate compared with other patients. Furthermore, patients with both conditions had a $48 \%$ increase in the risk of all-cause hospitalization and three times the risk of death than would have been predicted by the sum of the independent risks from either condition alone. However, statistical tests for interaction were not significant, so that synergy was unconfirmed.

Hospitalization for respiratory problems may be associated with a subsequent decline in cognitive function. Ambrosino et al studied 63 patients hospitalized for an exacerbation of COPD that required mechanical ventilation and found that patients' cognitive status was significantly worse at discharge (according to the MMSE) compared with controls. ${ }^{70}$ Likewise, patients discharged after a COPD exacerbation had significantly worse cognitive function than stable outpatients with COPD; ${ }^{68} 57 \%$ of patients discharged after a COPD exacerbation were considered impaired and $20 \%$ had pathologic impairment. Whether the patients in 
these studies had undetected cognitive impairment that preceded the exacerbation or whether cognitive impairment developed because of the exacerbation is unclear. Similar findings have been reported by other groups. ${ }^{21,71}$

Preliminary data suggest that patients with both COPD and cognitive decline may have increased mortality. Fix et al reported that poor performance on cognitive testing in COPD patients was associated with increased mortality; ${ }^{72}$ patients who later died had scored significantly $(P<0.01)$ lower on neuropsychological tests than those who had survived. In patients with hypoxemic COPD, Antonelli-Incalzi et al demonstrated that while distance walked in 6 min and drawing impairment (landmark test) were risk factors for mortality, other factors such as partial pressure of oxygen in arterial blood, comorbid diseases, and the impairment of cognitive domains other than drawing were unrelated to the outcome. ${ }^{32}$

\section{Treatment for patients with COPD and cognitive disorders}

Limited evidence exists to show that, in patients with COPD and cognitive disorders, improved cognition is associated with improved clinical outcomes such as exacerbation rate, compliance with medication, hospitalization, or quality of life. Treatments including oxygen therapy, pulmonary rehabilitation (PR), telemedicine, and pharmacologic therapy seem to be efficacious in small cohorts of patients, ${ }^{73-78}$ however, prospective longitudinal studies evaluating associations between cognitive improvements in other COPD outcomes in large diverse populations of COPD patients are lacking.

Oxygen therapy is an established treatment for cognitive deficits and COPD that attempts to reverse the putative effects of hypoxemia on the central nervous system. More than 40 years ago, Block et al demonstrated improvements in cognitive testing in 12 patients with severe hypoxemic COPD after 1 month of treatment with supplemental oxygen. ${ }^{79}$ In a landmark article that compared continuous oxygen therapy to nocturnal oxygen therapy in patients with COPD, researchers for the Nocturnal Oxygen Therapy Trial (NOTT) noted that continuous oxygen therapy was associated with a lower mortality than nocturnal oxygen therapy. ${ }^{73}$ The reason for this difference was not clear, but follow-up of a cohort of the NOTT patients demonstrated that patients who received continuous oxygen therapy had improved cognitive status. ${ }^{80}$ In addition, Hjalmarsen et al studied a small cohort of patients treated with continuous oxygen therapy for 3 months and found trends for improvement in neuropsychological functioning and cerebral blood flow compared with age-matched healthy controls. ${ }^{74}$
As previously noted, Thakur et al demonstrated that the use of continuous supplemental oxygen reduced the risk of cognitive impairment. ${ }^{64}$ It is noteworthy that the Thakur study was an observational study that examined oxygen use as a risk factor for cognitive deficits and was not a prospective treatment trial. In contrast, Dal Negro et al compared 73 patients with COPD who received continuous oxygen treatment with 73 patients with COPD who received oxygen "as needed." Based on a battery of four tests, those patients who received continuous oxygen demonstrated improved cognition, but the findings are limited because the nonrandomized study allowed patients to self-select their oxygen treatment option. Although long-term oxygen treatment may benefit cognitive deficits in hypoxemic COPD patients, short-term use seems to be ineffective. Pretto and McDonald, for example, reported that acute oxygen use failed to improve simulated driving performance or neurocognitive function in a small group of hypoxemic COPD patients. ${ }^{82}$

$\mathrm{PR}$, which comprises individualized exercise programs and education for patients with chronic respiratory impairment, ${ }^{83}$ has been proposed as a treatment to improve cognition in patients with COPD, since diminished aerobic fitness is a proven risk factor for cognitive impairment in these patients. ${ }^{45}$ Kozora and Make examined the effects of a 3-week PR treatment program in 30 COPD patients. ${ }^{75}$ Patients enrolled in the PR program demonstrated improved cognition $(P<0.05)$ as well as increased exercise capacity compared to untreated COPD patients and healthy control subjects. Emery et al studied 79 patients with COPD whom they randomized to exercise, education, and stress management; education and stress management without exercise; or a waiting list. ${ }^{84}$ Patients in the exercise arm demonstrated increased verbal fluency but no improvement in tests of attention and motor speed compared with patients either not assigned to education and stress management or on a waiting list.

Etnier and Berry examined a group of 40 patients with COPD who initially entered a 3-month exercise program. ${ }^{85}$ Cognitive functioning improved after this program. Subsequently, they split the group into a cohort that continued in the exercise program for 15 months and a cohort that discontinued the program. Cognitive function was not different between the long-term cohort and the terminated cohort, suggesting that short-term exercise may be sufficient to realize sustained cognitive benefits in patients with COPD. This contrasts with findings of Emery et al who followed patients for 1 year after completion of a 10-week exercise program. ${ }^{86}$ The $39 \%$ of patients who continued to exercise maintained their cognitive improvements, whereas 
the patients who discontinued exercise experienced a decline in cognition. These authors subsequently investigated the effects of a single exercise session on cognition, comparing 29 COPD patients with 29 matched healthy controls. ${ }^{76}$ A single exercise session improved the COPD patients' performance on a verbal fluency test. The general association between exercise and improved outcomes in COPD is likely multifactorial, but improved aerobic capacity, increased ability to accomplish tasks of daily living, and improved mood may be involved.

Investigators have also explored telemedicine (eg, delivery of COPD education or coping skills training by phone or computer ${ }^{87}$ ) as a potential treatment for cognitively impaired patients with COPD. In the Virtual Hospital Trial in Denmark, the effect of telemedicine on cognition following a COPD exacerbation was studied. ${ }^{77}$ After screening 647 patients admitted to an emergency department, 58 were eligible for the study based on a diagnosis of COPD exacerbation. Eligible patients were randomized into two groups: treatment via hospitalization $(\mathrm{n}=22)$ and treatment at home using telemedicine $(n=22)$. The results of a battery of cognitive tests showed no significant difference in cognition between the groups, suggesting patients with exacerbations were able to manage the telemedicine-based treatment despite the reduced cognitive function often observed in COPD patients.

Limited data exist concerning the impact of pharmacological therapies on either cognitive disorders or psychological conditions in COPD patients. In a mouse model of Down syndrome, the administration of formoterol, a longacting beta- 2 agonist used to treat COPD, improved synaptic density and cognitive function. ${ }^{88}$ A study in a rodent model demonstrated that roflumilast, a phosphodiesterase-4 inhibitor indicated for the treatment of COPD, may be associated with improved cognition. ${ }^{89}$ Definitive studies associating specific pharmacologic treatments for COPD with improved cognitive or psychological outcomes in patients with COPD do not exist. Interestingly, in a cohort of elderly asthma patients, improved asthma control was associated with improved cognitive function; ${ }^{78}$ however, these findings were not confirmed in a population of elderly urban dwellers with asthma (or with COPD). ${ }^{90}$ Further research is needed.

Cognitive impairment may negatively affect pharmacologic treatment outcomes in patients with COPD. For example, COPD patients with cognitive impairment may have difficulty utilizing hand-held device formulations of respiratory medications (eg, dry powder inhalers [DPIs], pressurized metered-dose inhalers), resulting in insufficient dosing that jeopardizes health outcomes, reduces quality of life, and further adds to the economic burden of COPD. ${ }^{91-93}$
Furthermore, cognitive impairment may make it difficult for patients to synchronize inhalation with activation, ${ }^{94,95}$ or patients may be unable to generate a sufficient inspiratory flow rate against the resistance of a breath-activated DPI to generate an effective aerosol..$^{92,93,96-98}$ In contrast, compared with hand-held devices, nebulizers require minimal cognitive ability and do not require hand-breath coordination, manual dexterity, or hand strength. ${ }^{96}$ Regardless of delivery device selection, however, pharmacological therapy in COPD patients with cognitive impairment should include training on correct use of the device as well as follow-up to ensure technique and treatment adherence.

The possible association of adverse health-related outcomes in patients with COPD and cognitive impairment merits further study. Should such an association be demonstrated, both adverse health-related outcomes and cognitive impairment could be the result of the underlying pathophysiology of COPD, now commonly viewed as a systemic disease. The mechanism by which cognitive impairment leads to adverse outcomes in COPD patients would need to be further elucidated. The authors speculate that the inability of patients to follow treatment regimens and maintain medical follow-up may play an important role.

\section{Psychiatric disorders}

In addition to cognitive disorders, patients with COPD are susceptible to psychiatric disorders such as depression and anxiety (Table 1)..$^{9,99}$ The occurrence of psychiatric disorders in COPD and the clinical outcomes in patients with COPD and psychiatric disorders are summarized in the following sections.

\section{Occurrence of psychiatric disorders in COPD}

\section{Prevalence}

High rates of depression and anxiety, at both clinical and subclinical levels, have been observed in patients with COPD,${ }^{100}$ with $6 \%-80 \%$ of patients suffering from anxiety and depressive symptoms and up to $55 \%$ suffering from anxiety and mood disorders ${ }^{101}$ (ie, distress at a level that interferes with daily functioning). The detection of high levels of psychological distress and the diagnosis of psychiatric disorders may be challenging in patients with COPD due to a number of factors: 1 ) the failure of patients and health care providers to recognize symptoms of anxiety or depression as psychological distress rather than symptoms of COPD, 2) the perception that depression and anxiety are "normal" reactions to having an incurable chronic disease rather than a marker of poor psychosocial adjustment, 3 ) fewer opportunities to 
detect distress due to the increased avoidance and social isolation that often accompanies COPD, and 4) the lack of systematic screening for psychological distress as part of routine care. ${ }^{102,103}$ It has been reported that primary care physicians fail to diagnose depression in more than half of depressed patients, which indicates a critical need to improve both the recognition and treatment of psychological distress among COPD patients. ${ }^{104}$

\section{Risk factors}

The precise causes of depression and anxiety in patients with COPD are not known; however, they are likely due to a complex interaction between physiological, behavioral, and psychosocial factors. ${ }^{99,105}$ Cigarette smoking has long been recognized as the primary cause of COPD in developed countries, ${ }^{2,106}$ and individuals with psychiatric comorbidities are twice as likely to be cigarette smokers relative to those without psychiatric comorbidities, ${ }^{107}$ suggesting that psychiatric morbidity could precede the development of COPD.

Other risk factors for the development of depression and anxiety involve poor psychosocial adaptation to having COPD. For example, the chronic and progressive nature of COPD, characterized by frequent episodes of acute exacerbations that often lead to hospital admissions, may cause anxiety, hopelessness, helplessness, and depressed mood. In a population-based sample of those with and without COPD $(n=476)$, Lu et $\mathrm{al}^{108}$ found that stress related to decreased energy, anxiety, and fear/panic in response to breathing difficulties was associated with increased depressive symptoms and impaired quality of life among patients with COPD compared to age-matched controls. Excessive dyspnea experienced at rest and/or during physical exertion that is not relieved by medication may also be traumatic for some and lead to increased anxiety and somatic hypervigilance. ${ }^{109}$ Teixeira et al ${ }^{109}$ examined the prevalence of post-traumatic stress disorder (PTSD) in patients with COPD and reported that one-third of patients met criteria for PTSD. Finally, the fact that COPD is typically diagnosed later in life, when patients are more likely to experience age-related losses (retirement, death of loved ones, diminishing social networks), may increase feelings of loneliness and may also trigger symptoms of depression and anxiety. ${ }^{110}$

\section{Assessment}

Because of significant overlap of certain symptoms of depression and anxiety (eg, low mood, loss of interest, decreased energy) with those of COPD (eg, fatigue, sleep disturbance, loss of ability to engage in pleasurable activities), ${ }^{111}$ it is important to assess psychological distress using validated questionnaires and/or interviews. Some of the most common symptom questionnaires include the Hospital Anxiety and Depression Scale, ${ }^{112}$ the Beck Depression Inventory, and the Beck Anxiety Inventory. ${ }^{113,114}$ Mood and anxiety disorders should be assessed by a structured interview that uses diagnostic criteria (ie, $\mathrm{DSM}^{25}$ ). Interviews include the Structured Clinical Interview for DSM ${ }^{115}$ and the Anxiety Disorders Interview Schedule for DSM. ${ }^{116}$ If time and resource limitations preclude the administration of a formal interview, shorter semistructured screening interviews are also available, such as the Primary Care Evaluation of Mental Disorders (PRIME-MD). ${ }^{117}$ The PRIME-MD questionnaire was designed to detect the most common DSM disorders that present in primary and tertiary care settings. It uses diagnostic algorithms to generate diagnoses based on DSM criteria that exhibit comparable reliability, sensitivity, and specificity to longer structured psychological interviews. ${ }^{117}$ The questionnaire takes between 10 and 15 min to administer and score and has been used extensively to assess psychiatric disorders in chronic disease populations. ${ }^{118-120}$

\section{Clinical outcomes in patients with COPD and psychiatric disorders}

Several negative consequences are associated with untreated depression and anxiety among COPD patients. Numerous studies have shown that COPD patients with comorbid depression and anxiety are at greater risk of having exacerbations and have higher rates of emergency visits and hospitalizations (and when hospitalized, have longer lengths of stay). COPD patients with comorbid depression and anxiety also exhibit greater symptom burden, increased disability, and poorer social functioning than do patients with COPD alone. ${ }^{121-124}$ Finally, evidence suggests that depression may be a risk factor for mortality among COPD patients. A recent systematic review of long-term follow-up studies found that the presence of depression among COPD patients increased their risk of death by $83 \%$, particularly among men. ${ }^{125}$ The review also revealed that depression had a greater impact on mortality risk among COPD patients relative to those with other chronic diseases such as heart and kidney disease and cancer, suggesting that depression may be particularly detrimental to COPD survival.

\section{Mechanisms linking psychiatric disorders to worse COPD outcomes}

Although the exact reasons for worse outcomes in COPD patients with psychiatric comorbidity remain unclear, evidence suggests that they may be related to poorer health behaviors and worse disease self-management. Depression 
and anxiety are associated with feelings of helplessness, withdrawal, hopelessness, and fear, which may lower confidence in patients' ability to self-manage their disease. COPD patients with depression have been shown to have worse adherence to medical treatment ${ }^{101,111,123,124}$ and are more likely to be persistent smokers ${ }^{108,109}$ relative to nondepressed patients. ${ }^{121,122}$ Depression and anxiety are also associated with impaired cognitive function (distorted thoughts and beliefs) that could lead patients to misinterpret symptoms such as breathlessness, leading to over-reporting and increases in health care and medication use. ${ }^{126}$

Finally, depression and anxiety could worsen COPD outcomes through various psychophysiological pathways, including autonomic nervous system and immune dysregulation. ${ }^{127}$ It has been well documented that chronic stress can lead to persistent activation of the sympathetic nervous system (SNS) and an increased risk for the development of cardiovascular disease. ${ }^{128}$ This persistent activation of the SNS may also increase the risk for exacerbations in COPD patients via autonomic pathways. With regard to immune mechanisms, Cohen et al have shown that individuals who experience chronic stress are at higher risk of infection when exposed to viral and bacterial infections such as the common cold. ${ }^{129,130}$ This suggests that COPD patients experiencing chronic depression and/or anxiety may have compromised immune responses, leading to an increased risk of exacerbations in this highly vulnerable population. ${ }^{131,132}$

Taken together, research to date indicates that COPD patients with comorbid depression and anxiety may have a higher symptom burden and worse outcomes. This may be the result of poorer self-management, cognitive factors, or psychophysiological mechanisms, pointing to a need to improve detection and treatment of psychiatric disorders in patients with COPD.

\section{Treating patients with COPD and psychiatric disorders}

Several treatment options exist for COPD patients suffering from anxiety and/or depression, including psychotherapy, pharmacotherapy, and exercise within the context of a comprehensive PR program. Similar to patients with COPD and cognitive disorders, however, limited evidence exists that treatment of psychiatric disorders in patients with COPD is associated with improved COPD outcomes, and prospective longitudinal studies evaluating such associations in large diverse populations of COPD patients are lacking.

Cognitive behavioral therapy (CBT) is regarded as a first line of psychotherapy for older patients with mild to moderate depression depending on availability and patients' preference. ${ }^{133}$ It focuses on identifying and reframing negative, dysfunctional thoughts while participating in pleasurable and social activities. Hynninen et $\mathrm{al}^{134}$ conducted a randomized, controlled trial that compared 8 weeks of CBT $(n=25)$ to enhanced standard care $(n=26)$ in COPD patients with comorbid depression. CBT resulted in improvement in symptoms of anxiety and depression compared with the enhanced standard care group, with improvements maintained at 8 months. Farver-Vestergaard et $\mathrm{al}^{135}$ reported that CBT was superior to usual care in improving psychological well-being (depression) in patients with COPD $(P<0.04)$. However, a similar review reported a nonsignificant trend in favor of CBT over usual care for the reduction of anxiety and depression in COPD patients. ${ }^{136}$ Although mixed, the literature indicates that CBT is likely effective for reducing anxiety and depression among COPD patients.

The National Institute for Health and Care Excellence guideline for the management of depression and anxiety in older people recommends the use of antidepressants in patients with moderate to severe physical illness, including COPD. ${ }^{133}$ It suggests the use of selective serotonin reuptake inhibitors (SSRIs) as a first-line treatment of depression or anxiety (due to their better safety record compared with tricyclic antidepressants [TCAs]). However, a recent systematic review examined the efficacy of both SSRIs and TCAs in patients with COPD and found inconclusive evidence in clinical trials. ${ }^{137}$ The trials were small, and depressed COPD patients had poor adherence to treatment, were often unwilling to accept antidepressant prescriptions, and had a high dropout rate due to intolerance of side effects. To date, it remains unclear whether antidepressants can induce remission of depression or improve symptoms or physiological indices of COPD. ${ }^{137}$ Therefore, well-controlled clinical trials are required to examine the efficacy of SSRIs in depressed and anxious COPD patients.

Finally, exercise treatment as part of a comprehensive PR program (individualized exercise and education) has also demonstrated reductions in levels of depressive and anxiety symptoms among COPD patients when compared with usual care. ${ }^{138,139}$ For example, a recent noncontrolled intensive 3-week outpatient PR program (6 h per day, 5 days per week) showed significant improvements in depression and anxiety in patients with COPD. ${ }^{140}$ Although exercise has been shown to reduce psychological distress in the short term (ie, 12 weeks), the long-term benefits of exercise in reducing anxiety and depression in patients with COPD are unknown. Further work is needed to evaluate the long-term effects of exercise on psychological distress levels among COPD patients. 
In summary, depression and anxiety (both symptoms and clinical disorders) are prevalent among COPD patients and are associated with worse outcomes, including higher exacerbation rates, greater functional limitations, and increased mortality. This may be the result of poorer selfmanagement, cognitive factors, or psychophysiological mechanisms. Smoking is a common feature of both COPD and psychiatric disorders and may be a common risk factor. Treatments including CBT, antidepressants, and exercise in the context of PR all show promise for treating depression and anxiety in COPD patients.

\section{Summary and conclusion}

Patients with COPD suffer from various comorbidities that many in the scientific community now view as constitutive elements of the disease. Prominent among these are cognitive and psychiatric disorders, both of which implicate important health care outcomes for these patients. Preliminary research suggests that some pharmacologic and nonpharmacologic interventions have the potential to ameliorate the negative health care outcomes associated with cognitive and/or psychiatric disorders, but definitive data do not yet exist. Clinicians caring for these patients must become familiar with tools to screen for these associated conditions. In the future, treatments may become available that will not only modify the course of these neuropsychological disorders but also potentially modify the critical outcomes of COPD.

\section{Acknowledgments}

Manuscript editing support was provided by Mylan Pharmaceuticals (Canonsburg, PA). Roger J Hill, PhD of Ashfield Healthcare Communications (Middletown, CT) reviewed and revised the manuscript with input from the authors, and Paula Stuckart of Ashfield Healthcare Communications copyedited and styled the manuscript per journal requirements.

\section{Disclosure}

Salary support was provided by Investigator Awards from the Canadian Institutes of Health Research (CIHR) and the Fonds de la Recherche du Québec - Santé (FRQS) (Lavoie). The authors report no other conflicts of interest in this work.

\section{References}

1. Mannino DM, Homa DM, Akinbami LJ, Ford ES, Redd SC. Chronic obstructive pulmonary disease surveillance: United States, 1971-2000. MMWR Surveill Summ. 2002;51:1-16.

2. Pauwels RA, Rabe KF. Burden and clinical features of chronic obstructive pulmonary disease (COPD). Lancet. 2004;364(9434):613-620.
3. National Heart, Lung, and Blood Institute. Data fact sheet. Chronic obstructive pulmonary disease. Available from: http://www.apsfa.org/ docs/copd_fact.pdf. Accessed June 6, 2016.

4. Public Health Agency of Canada. Chronic Pulmonary Obstructive Disease (COPD). Ottawa: Public Health Agency of Canada. Available from: http://www.phac-aspc.Gc.ca/cd-mc/publications/copd-mpoc/ ff-rr-2011-eng.php. Accessed March 24, 2016.

5. Cdc.gov. Centers for Disease Control and Prevention. National Center for Health Statistics. Data brief 63: Chronic obstructive pulmonary disease among adults aged 18 and over in the United States, 1998-2009. Available from: http://www.cdc.gov/nchs/data/databriefs/db63_tables. pdf\#2. Accessed March 4, 2016.

6. U.S. Department of Health and Human Services. The health benefits of smoking cessation. U.S. Department of Health and Human Services, public health service, centers for disease control, center for chronic disease prevention and health promotion, office on smoking and health. DHHS publication no. (CDC) 90-8416; 1990. Available from: https://profiles.nlm.nih.gov/NN/B/B/C/T/. Accessed June 6, 2016.

7. Rabe KF, Hurd S, Anzueto A, et al. Global strategy for the diagnosis, management, and prevention of chronic obstructive pulmonary disease: GOLD executive summary. Am J Respir Crit Care Med. 2007;176(6): $532-555$.

8. Mannino DM, Thorn D, Swensen A, Holguin F. Prevalence and outcomes of diabetes, hypertension and cardiovascular disease in COPD. Eur Respir J. 2008;32(4):962-969.

9. Fabbri LM, Luppi F, Beghe B, Rabe KF. Complex chronic comorbidities of COPD. Eur Respir J. 2008;31(1):204-212.

10. Sidney S, Sorel M, Quesenberry CP Jr, DeLuise C, Lanes S, Eisner MD. COPD and incident cardiovascular disease hospitalizations and mortality: Kaiser permanente medical care program. Chest. 2005;128(4): 2068-2075.

11. Brody JS, Spira A. State of the art. Chronic obstructive pulmonary disease, inflammation, and lung cancer. Proc Am Thorac Soc. 2006; 3(6):535-537.

12. Young RP, Hopkins RJ, Christmas T, Black PN, Metcalf P, Gamble GD. COPD prevalence is increased in lung cancer, independent of age, sex and smoking history. Eur Respir J. 2009;34(2):380-386.

13. Marquis K, Maltais F, Duguay V, et al. The metabolic syndrome in patients with chronic obstructive pulmonary disease. J Cardiopulm Rehabil. 2005;25(4):226-232; discussion 233-234.

14. Watz H, Waschki B, Kirsten A, et al. The metabolic syndrome in patients with chronic bronchitis and COPD: frequency and associated consequences for systemic inflammation and physical inactivity. Chest. 2009; 136(4):1039-1046.

15. Biskobing DM. COPD and osteoporosis. Chest. 2002;121(2): 609-620.

16. Ferguson GT, Calverley PM, Anderson JA, et al. Prevalence and progression of osteoporosis in patients with COPD: results from the towards a revolution in COPD health study. Chest. 2009;136(6):1456-1465.

17. Parappil A, Depczynski B, Collett P, Marks GB. Effect of comorbid diabetes on length of stay and risk of death in patients admitted with acute exacerbations of COPD. Respirology. 2010;15(6):918-922.

18. Barr RG, Celli BR, Mannino DM, et al. Comorbidities, patient knowledge, and disease management in a national sample of patients with COPD. Am J Med. 2009;122(4):348-355.

19. Anderson D, Macnee W. Targeted treatment in COPD: a multi-system approach for a multi-system disease. Int J Chron Obstruct Pulmon Dis. 2009;4:321-335.

20. Dodd JW, Getov SV, Jones PW. Cognitive function in COPD. Eur Respir J. 2010;35(4):913-922.

21. Schou L, Ostergaard B, Rasmussen LS, Rydahl-Hansen S, Phanareth K. Cognitive dysfunction in patients with chronic obstructive pulmonary disease - a systematic review. Respir Med. 2012;106(8):1071-1081.

22. Guerrero A, Piasecki M. Problem-Based Behavioral Science and Psychiatry. New York, NY: Springer; 2008.

23. Torpy JM, Burke AE, Glass RM. Jama patient page. Delirium. JAMA. 2010;304(7):814. 
24. Torpy JM, Lynm C, Glass RM. Jama patient page. Dementia. JAMA. 2008;300(19):2330.

25. American Psychiatric Association. Diagnostic and Statistical Manual of Mental Disorders (DSM- $5^{\circledR}$ ). 2013; Available from: https://goo.gl/ X6zEGJ. Accessed July 22, 2016.

26. Schacter DL. Memory, amnesia, and frontal lobe dysfunction. Psychobiology. 1987;15(1):21-36.

27. Torpy JM, Lynm C, Glass RM. Jama patient page. Mild cognitive impairment. JAMA. 2008;300(13):1610.

28. Feldman HH, Jacova C. Mild cognitive impairment. Am J Geriatr Psychiatry. 2005;13(8):645-655.

29. Gauthier S, Reisberg B, Zaudig M, et al. Mild cognitive impairment. Lancet. 2006;367(9518):1262-1270.

30. Petersen RC, Stevens JC, Ganguli M, Tangalos EG, Cummings JL, DeKosky ST. Practice parameter: early detection of dementia: mild cognitive impairment (an evidence-based review). Report of the quality standards subcommittee of the American Academy of Neurology. Neurology. 2001;56(9):1133-1142.

31. Bruscoli M, Lovestone S. Is MCI really just early dementia? A systematic review of conversion studies. Int Psychogeriat. 2004;16(2):129-140.

32. Antonelli-Incalzi R, Corsonello A, Pedone C, et al. Drawing impairment predicts mortality in severe COPD. Chest. 2006;130(6):1687-1694.

33. Martinez CH, Richardson CR, Han MK, Cigolle CT. Chronic obstructive pulmonary disease, cognitive impairment, and development of disability: the health and retirement study. Ann Am Thorac Soc. 2014; 11(9):1362-1370.

34. Villeneuve S, Pepin V, Rahayel S, et al. Mild cognitive impairment in moderate to severe COPD: a preliminary study. Chest. 2012;142(6): $1516-1523$.

35. Ozge C, Ozge A, Unal O. Cognitive and functional deterioration in patients with severe COPD. Behav Neurol. 2006;17(2):121-130.

36. Dal Negro RW, Bonadiman L, Tognella S, Bricolo FP, Turco P. Extent and prevalence of cognitive dysfunction in chronic obstructive pulmonary disease, chronic non-obstructive bronchitis, and in asymptomatic smokers, compared to normal reference values. Int J Chron Obstruct Pulmon Dis. 2014;9:675-683.

37. Liao KM, Ho CH, Ko SC, Li CY. Increased risk of dementia in patients with chronic obstructive pulmonary disease. Medicine (Baltimore). 2015;94(23):e930.

38. Fioravanti M, Nacca D, Amati S, Buckley AE, Bisetti A. Chronic obstructive pulmonary disease and associated patterns of memory decline. Dementia. 1995;6(1):39-48.

39. Incalzil RA, Bellia V, Maggi S, et al. Mild to moderate chronic airways disease does not carry an excess risk of cognitive dysfunction. Aging Clin Exp Res. 2002;14(5):395-401.

40. Isoaho R, Puolijoki H, Huhti E, Laippala P, Kivela SL. Chronic obstructive pulmonary disease and cognitive impairment in the elderly. Int Psychogeriatr. 1996;8(1):113-125.

41. Liesker JJ, Postma DS, Beukema RJ, et al. Cognitive performance in patients with COPD. Respir Med. 2004;98(4):351-356.

42. Rusanen M, Ngandu T, Laatikainen T, Tuomilehto J, Soininen H, Kivipelto M. Chronic obstructive pulmonary disease and asthma and the risk of mild cognitive impairment and dementia: a population based CAIDE study. Curr Alzheimer Res. 2013;10(5):549-555.

43. Singh B, Mielke MM, Parsaik AK, et al. A prospective study of chronic obstructive pulmonary disease and the risk for mild cognitive impairment. JAMA Neurol. 2014;71(5):581-588.

44. Tulek B, Atalay NB, Yildirim G, Kanat F, Suerdem M. Cognitive function in chronic obstructive pulmonary disease: relationship to global initiative for chronic obstructive lung disease 2011 categories. Respirology. 2014;19(6):873-880.

45. Etnier J, Johnston R, Dagenbach D, Pollard RJ, Rejeski WJ, Berry M. The relationships among pulmonary function, aerobic fitness, and cognitive functioning in older COPD patients. Chest. 1999;116(4):953-960.

46. Zhou G, Liu J, Sun F, et al. Association of chronic obstructive pulmonary disease with cognitive decline in very elderly men. Dement Geriatr Cogn Dis Extra. 2012;2:219-228.
47. Ortapamuk H, Naldoken S. Brain perfusion abnormalities in chronic obstructive pulmonary disease: comparison with cognitive impairment. Ann Nucl Med. 2006;20(2):99-106.

48. Zheng GQ, Wang Y, Wang XT. Chronic hypoxia-hypercapnia influences cognitive function: a possible new model of cognitive dysfunction in chronic obstructive pulmonary disease. Med Hypotheses. 2008; 71(1):111-113.

49. Antonelli-Incalzi R, Corsonello A, Trojano L, et al. Screening of cognitive impairment in chronic obstructive pulmonary disease. Dement Geriatr Cogn Disord. 2007;23(4):264-270.

50. Crisan AF, Oancea C, Timar B, Fira-Mladinescu O, Crisan A, Tudorache V. Cognitive impairment in chronic obstructive pulmonary disease. PLoS One. 2014;9(7):e102468.

51. Park SK, Larson JL. Cognitive function as measured by trail making test in patients with COPD. West $J$ Nurs Res. 2015;37(2):236-256.

52. Prigatano GP, Parsons O, Wright E, Levin DC, Hawryluk G. Neuropsychological test performance in mildly hypoxemic patients with chronic obstructive pulmonary disease. J Consult Clin Psychol. 1983;51(1):108-116.

53. Verma N, Beretvas SN, Pascual B, Masdeu JC, Markey MK; Alzheimer's Disease Neuroimaging Initiative. New scoring methodology improves the sensitivity of the Alzheimer's disease assessment scale-cognitive subscale (ADAS-Cog) in clinical trials. Alzheimers Res Ther. 2015;7(1):1-17.

54. Kirkil G, Tug T, Ozel E, Bulut S, Tekatas A, Muz MH. The evaluation of cognitive functions with $\mathrm{p} 300$ test for chronic obstructive pulmonary disease patients in attack and stable period. Clin Neurol Neurosurg. 2007:109(7):553-560.

55. Reeves RR, Struve FA, Patrick G, Payne DK, Thirstrup LL. Auditory and visual p300 cognitive evoked responses in patients with COPD: relationship to degree of pulmonary impairment. Clin Electroencephalogr. 1999;30(3):122-125.

56. Incalzi RA, Gemma A, Marra C, Muzzolon R, Capparella O, Carbonin P. Chronic obstructive pulmonary disease. An original model of cognitive decline. Am Rev Respir Dis. 1993;148(2):418-424.

57. Ott A, Andersen K, Dewey ME, et al. Effect of smoking on global cognitive function in nondemented elderly. Neurology. 2004;62(6):920-924.

58. Borson S, Scanlan J, Friedman S, et al. Modeling the impact of COPD on the brain. Int J Chron Obstruct Pulmon Dis. 2008;3(3):429-434.

59. Lahousse L, Tiemeier H, Ikram MA, Brusselle GG. Chronic obstructive pulmonary disease and cerebrovascular disease: a comprehensive review. Respir Med. 2015;109(11):1371-1380.

60. Urbano F, Mohsenin V. Chronic obstructive pulmonary disease and sleep: the interaction. Panminerva Med. 2006;48(4):223-230.

61. van Ede L, Yzermans CJ, Brouwer HJ. Prevalence of depression in patients with chronic obstructive pulmonary disease: a systematic review. Thorax. 1999;54(8):688-692.

62. Report of the national chronic obstructive pulmonary disease audit: clinical audit of COPD exacerbations admitted to acute NHS units across the UK. 2008; Available from: http://bit.ly/2gLjlGV. Accessed November 23, 2016.

63. Moss M, Franks M, Briggs P, Kennedy D, Scholey A. Compromised arterial oxygen saturation in elderly asthma sufferers results in selective cognitive impairment. J Clin Exp Neuropsychol. 2005;27(2):139-150.

64. Thakur N, Blanc PD, Julian LJ, et al. COPD and cognitive impairment: the role of hypoxemia and oxygen therapy. Int J Chron Obstruct Pulmon Dis. 2010;5:263-269.

65. Antonelli Incalzi R, Marra C, Giordano A, et al. Cognitive impairment in chronic obstructive pulmonary disease - a neuropsychological and spect study. J Neurol. 2003;250(3):325-332.

66. Li J, Fei GH. The unique alterations of hippocampus and cognitive impairment in chronic obstructive pulmonary disease. Respir Res. 2013; $14: 140$

67. Dodd JW, Chung AW, van den Broek MD, Barrick TR, Charlton RA, Jones PW. Brain structure and function in chronic obstructive pulmonary disease: a multimodal cranial magnetic resonance imaging study. Am J Respir Crit Care Med. 2012;186(3):240-245. 
68. Dodd JW, Charlton RA, van den Broek MD, Jones PW. Cognitive dysfunction in patients hospitalized with acute exacerbation of COPD. Chest. 2013;144(1):119-127.

69. Chang SS, Chen S, McAvay GJ, Tinetti ME. Effect of coexisting chronic obstructive pulmonary disease and cognitive impairment on health outcomes in older adults. J Am Geriatr Soc. 2012;60(10):1839-1846.

70. Ambrosino N, Bruletti G, Scala V, Porta R, Vitacca M. Cognitive and perceived health status in patient with chronic obstructive pulmonary disease surviving acute on chronic respiratory failure: a controlled study. Intensive Care Med. 2002;28(2):170-177.

71. Ozyemisci-Taskiran O, Bozkurt SO, Kokturk N, Karatas GK. Is there any association between cognitive status and functional capacity during exacerbation of chronic obstructive pulmonary disease? Chron Respir Dis. 2015;12(3):247-255.

72. Fix AJ, Daughton D, Kass I, Bell CW, Golden CJ. Cognitive functioning and survival among patients with chronic obstructive pulmonary disease. Int J Neurosci. 1985;27(1-2):13-17.

73. Nocturnal Oxygen Therapy Trial Group. Continuous or nocturnal oxygen therapy in hypoxemic chronic obstructive lung disease: a clinical trial. Ann Intern Med. 1980;93(3):391-398.

74. Hjalmarsen A, Waterloo K, Dahl A, Jorde R, Viitanen M. Effect of longterm oxygen therapy on cognitive and neurological dysfunction in chronic obstructive pulmonary disease. Eur Neurol. 1999;42(1):27-35.

75. Kozora E, Make BJ. Cognitive improvement following rehabilitation in patients with COPD. Chest. 2000;117(5 Suppl 1):249S [Abstract].

76. Emery CF, Honn VJ, Frid DJ, Lebowitz KR, Diaz PT. Acute effects of exercise on cognition in patients with chronic obstructive pulmonary disease. Am J Respir Crit Care Med. 2001;164(9):1624-1627.

77. Schou L, Ostergaard B, Rasmussen LS, et al. Telemedicine-based treatment versus hospitalization in patients with severe chronic obstructive pulmonary disease and exacerbation: effect on cognitive function. A randomized clinical trial. Telemed J E Health. 2014;20(7):640-646.

78. Bozek A, Krajewska J, Jarzab J. The improvement of cognitive functions in patients with bronchial asthma after therapy. J Asthma. 2010;47(10):1148-1152.

79. Block AJ, Castle JR, Keitt AS. Chronic oxygen therapy. Treatment of chronic obstructive pulmonary disease at sea level. Chest. 1974;65(3):279-288.

80. Heaton RK, Grant I, McSweeny AJ, Adams KM, Petty TL. Psychologic effects of continuous and nocturnal oxygen therapy in hypoxemic chronic obstructive pulmonary disease. Arch Intern Med. 1983; 143(10):1941-1947.

81. Dal Negro RW, Bonadiman L, Bricolo FP, Tognella S, Turco P. Cognitive dysfunction in severe chronic obstructive pulmonary disease (COPD) with or without long-term oxygen therapy (ltot). Multidiscip Respir Med. 2015;10(1):17.

82. Pretto JJ, McDonald CF. Acute oxygen therapy does not improve cognitive and driving performance in hypoxaemic COPD. Respirology. 2008;13(7):1039-1044.

83. Bolton CE, Bevan-Smith EF, Blakey JD, et al. British thoracic society guideline on pulmonary rehabilitation in adults. Thorax. 2013;68(Suppl 2):ii1-ii30.

84. Emery CF, Schein RL, Hauck ER, MacIntyre NR. Psychological and cognitive outcomes of a randomized trial of exercise among patients with chronic obstructive pulmonary disease. Health Psychol. 1998; 17(3):232-240.

85. Etnier JL, Berry M. Fluid intelligence in an older COPD sample after short- or long-term exercise. Med Sci Sports Exerc. 2001;33(10): 1620-1628.

86. Emery CF, Shermer RL, Hauck ER, Hsiao ET, MacIntyre NR. Cognitive and psychological outcomes of exercise in a 1-year follow-up study of patients with chronic obstructive pulmonary disease. Health Psychol. 2003;22(6):598-604.

87. Gregersen TL, Green A, Frausing E, Ringbaek T, Brondum E, Suppli Ulrik C. Do telemedical interventions improve quality of life in patients with COPD? A systematic review. Int J Chron Obstruct Pulmon Dis. 2016;11:809-822.
88. Dang V, Medina B, Das D, et al. Formoterol, a long-acting beta2 adrenergic agonist, improves cognitive function and promotes dendritic complexity in a mouse model of down syndrome. Biol Psychiatry. 2014; 75(3):179-188.

89. Vanmierlo T, Creemers P, Akkerman S, et al. The pde4 inhibitor roflumilast improves memory in rodents at non-emetic doses. Behav Brain Res. 2016;303:26-33.

90. Ray M, Sano M, Wisnivesky JP, Wolf MS, Federman AD. Asthma control and cognitive function in a cohort of elderly adults. $\mathrm{J} \mathrm{Am}$ Geriatr Soc. 2015;63(4):684-691.

91. Vestbo J, Hurd SS, Agusti AG, et al. Global strategy for the diagnosis, management, and prevention of chronic obstructive pulmonary disease: GOLD executive summary. Am J Respir Crit Care Med. 2013; 187(4):347-365.

92. Melani AS, Bonavia M, Cilenti V, et al. Inhaler mishandling remains common in real life and is associated with reduced disease control. Respir Med. 2011;105(6):930-938.

93. Taffet GE, Donohue JF, Altman PR. Considerations for managing chronic obstructive pulmonary disease in the elderly. Clin Interv Aging. 2014;9:23-30.

94. Quinet P, Young CA, Heritier F. The use of dry powder inhaler devices by elderly patients suffering from chronic obstructive pulmonary disease. Ann Phys Rehabil Med. 2010;53(2):69-76.

95. Zarowitz BJ, O'Shea T. Chronic obstructive pulmonary disease: prevalence, characteristics, and pharmacologic treatment in nursing home residents with cognitive impairment. J Manag Care Pharm. 2012;18(8):598-606.

96. Dhand R, Dolovich M, Chipps B, Myers TR, Restrepo R, Farrar JR. The role of nebulized therapy in the management of COPD: evidence and recommendations. COPD. 2012;9(1):58-72.

97. Barrons R, Pegram A, Borries A. Inhaler device selection: special considerations in elderly patients with chronic obstructive pulmonary disease. Am J Health Syst Pharm. 2011;68(13):1221-1232.

98. Dekhuijzen PN, Bjermer L, Lavorini F, Ninane V, Molimard M, Haughney J. Guidance on handheld inhalers in asthma and COPD guidelines. Respir Med. 2014;108(5):694-700.

99. Yohannes AM. Management of anxiety and depression in patients with COPD. Expert Rev Respir Med. 2008;2(3):337-347.

100. Manson JE, Skerrett PJ, Greenland P, VanItallie TB. The escalating pandemics of obesity and sedentary lifestyle. A call to action for clinicians. Arch Intern Med. 2004;164(3):249-258.

101. Yohannes AM, Willgoss TG, Baldwin RC, Connolly MJ. Depression and anxiety in chronic heart failure and chronic obstructive pulmonary disease: prevalence, relevance, clinical implications and management principles. Int J Geriatr Psychiatry. 2010;25(12):1209-1221.

102. Sirey JA, Bruce ML, Alexopoulos GS, Perlick DA, Friedman SJ, Meyers BS. Stigma as a barrier to recovery: perceived stigma and patient-rated severity of illness as predictors of antidepressant drug adherence. Psychiatr Serv. 2001;52(12):1615-1620.

103. Yohannes AM, Connolly MJ, Baldwin RC. A feasibility study of antidepressant drug therapy in depressed elderly patients with chronic obstructive pulmonary disease. Int J Geriatr Psychiatry. 2001;16(5):451-454.

104. Memel DS, Kirwan JR, Sharp DJ, Hehir M. General practitioners miss disability and anxiety as well as depression in their patients with osteoarthritis. Br J Gen Pract. 2000;50(457):645-648.

105. Divo M, Cote C, de Torres JP, et al. Comorbidities and risk of mortality in patients with chronic obstructive pulmonary disease. Am J Respir Crit Care Med. 2012;186(2):155-161.

106. Sethi JM, Rochester CL. Smoking and chronic obstructive pulmonary disease. Clin Chest Med. 2000;21(1):67-86, viii.

107. Wong ST, Manca D, Barber D, et al. The diagnosis of depression and its treatment in Canadian primary care practices: an epidemiological study. CMAJ Open. 2014;2(4):E337-E342.

108. Lu Y, Nyunt MSZ, Gwee X, et al. Life event stress and chronic obstructive pulmonary disease (COPD): associations with mental well-being and quality of life in a population-based study. BMJ open . 2012;2(6):e001674. 
109. Teixeira PJ, Porto L, Kristensen CH, Santos AH, Menna-Barreto SS, Do Prado-Lima PA. Post-traumatic stress symptoms and exacerbations in COPD patients. COPD. 2015;12(1):90-95.

110. Wiese BS. Geriatric depression: the use of antidepressants in the elderly. BCMJ. 2011;53(7):341-347.

111. Maurer J, Rebbapragada V, Borson S, et al. Anxiety and depression in COPD: current understanding, unanswered questions, and research needs. Chest. 2008;134(4 Suppl):43S-56S.

112. Zigmond AS, Snaith RP. The hospital anxiety and depression scale. Acta Psychiatr Scand. 1983;67(6):361-370.

113. Beck AT, Epstein N, Brown G, Steer RA. An inventory for measuring clinical anxiety: psychometric properties. J Consult Clin Psychol. 1988;56(6):893-897.

114. Beck AT, Steer RA, Carbin MG. Psychometric properties of the beck depression inventory: twenty-five years of evaluation. Clin Psychol Rev. 1988;8(1):77-100.

115. First MB, Spitzer RL, Gibbon M, Williams JB. Structured Clinical Interview for DSM-IV Axis I Disorders-Patient Edition (SCID-I/P, Version 2.0). New York: Biometrics Research Department, New York State Psychiatric Institute; 1995:722.

116. Di Nardo P, Moras K, Barlow DH, Rapee RM, Brown TA. Reliability of DSM-III-R anxiety disorder categories. Using the anxiety disorders interview schedule-revised (ADIS-R). Arch Gen Psychiatry. 1993; 50(4):251-256

117. Spitzer RL, Williams JB, Kroenke K, et al. Utility of a new procedure for diagnosing mental disorders in primary care. The Prime-MD 1000 study. JAMA. 1994;272(22):1749-1756.

118. Favreau H, Bacon SL, Labrecque M, Lavoie KL. Prospective impact of panic disorder and panic-anxiety on asthma control, health service use, and quality of life in adult patients with asthma over a 4-year follow-up. Psychosom Med. 2014;76(2):147-155.

119. Lavoie KL, Joseph M, Favreau H, et al. Prevalence of psychiatric disorders among patients investigated for occupational asthma: an overlooked differential diagnosis? Am J Respir Crit Care Med. 2013; 187(9):926-932.

120. Lavoie KL, Boudreau M, Plourde A, Campbell TS, Bacon SL. Association between generalized anxiety disorder and asthma morbidity. Psychosom Med. 2011;73(6):504-513.

121. Ng TP, Niti M, Tan WC, Cao Z, Ong KC, Eng P. Depressive symptoms and chronic obstructive pulmonary disease: effect on mortality, hospital readmission, symptom burden, functional status, and quality of life. Arch Intern Med. 2007;167(1):60-67.

122. Papaioannou AI, Bartziokas K, Tsikrika S, et al. The impact of depressive symptoms on recovery and outcome of hospitalised COPD exacerbations. Eur Respir J. 2013;41(4):815-823.

123. Laurin C, Moullec G, Bacon SL, Lavoie KL. The impact of psychological distress on exacerbation rates in COPD. Ther Adv Respir Dis. 2011;5(1):3-18.

124. Laurin C, Moullec G, Bacon SL, Lavoie KL. Impact of anxiety and depression on chronic obstructive pulmonary disease exacerbation risk. Am J Respir Crit Care Med. 2012;185(9):918-923.
125. Cuijpers P, Vogelzangs N, Twisk J, Kleiboer A, Li J, Penninx BW. Comprehensive meta-analysis of excess mortality in depression in the general community versus patients with specific illnesses. $\mathrm{Am} \mathrm{J}$ Psychiatry. 2014;171(4):453-462.

126. Dales RE, Spitzer WO, Schechter MT, Suissa S. The influence of psychological status on respiratory symptom reporting. Am Rev Respir Dis. 1989;139(6):1459-1463.

127. Liu LY, Coe CL, Swenson CA, Kelly EA, Kita H, Busse WW. School examinations enhance airway inflammation to antigen challenge. Am J Respir Crit Care Med. 2002;165(8):1062-1067.

128. Esler M. The sympathetic system and hypertension. Am J Hypertens. 2000;13(6 Pt 2):99S-105S.

129. Cohen S, Tyrrell DA, Smith AP. Negative life events, perceived stress, negative affect, and susceptibility to the common cold. J Pers Soc Psychol. 1993;64(1):131-140.

130. Cohen S, Tyrrell DA, Smith AP. Psychological stress and susceptibility to the common cold. N Engl J Med. 1991;325(9):606-612.

131. O'Leary A. Self-efficacy and health: behavioral and stress-physiological mediation. Cogn Ther Res. 1992;16(2):229-245.

132. Padgett DA, Glaser R. How stress influences the immune response. Trends Immunol. 2003;24(8):444-448.

133. NICE. Depression in adults: recognition and management. Clinical guideline; October 28, 2009. Available from: https://www.nice.org. uk/guidance/cg90/resources/depression-in-adults-recognition-andmanagement-975742636741. Accessed June 6, 2016.

134. Hynninen MJ, Bjerke N, Pallesen S, Bakke PS, Nordhus IH. A randomized controlled trial of cognitive behavioral therapy for anxiety and depression in COPD. Respir Med. 2010;104(7):986-994.

135. Farver-Vestergaard I, Jacobsen D, Zachariae R. Efficacy of psychosocial interventions on psychological and physical health outcomes in chronic obstructive pulmonary disease: a systematic review and meta-analysis. Psychother Psychosom. 2015;84(1):37-50.

136. Smith SM, Sonego S, Ketcheson L, Larson JL. A review of the effectiveness of psychological interventions used for anxiety and depression in chronic obstructive pulmonary disease. BMJ Open Respir Res. 2014; 1(1):e000042.

137. Yohannes AM, Alexopoulos GS. Pharmacological treatment of depression in older patients with chronic obstructive pulmonary disease: impact on the course of the disease and health outcomes. Drugs Aging. 2014;31(7):483-492.

138. Coventry PA, Hind D. Comprehensive pulmonary rehabilitation for anxiety and depression in adults with chronic obstructive pulmonary disease: systematic review and meta-analysis. J Psychosom Res. 2007; 63(5):551-565.

139. Alexopoulos GS, Sirey JA, Raue PJ, Kanellopoulos D, Clark TE, Novitch RS. Outcomes of depressed patients undergoing inpatient pulmonary rehabilitation. Am J Geriatr Psychiatry. 2006;14(5): 466-475.

140. von Leupoldt A, Taube K, Lehmann K, Fritzsche A, Magnussen H. The impact of anxiety and depression on outcomes of pulmonary rehabilitation in patients with COPD. Chest. 2011;140(3):730-736.
International Journal of COPD

\section{Publish your work in this journal}

The International Journal of COPD is an international, peer-reviewed journal of therapeutics and pharmacology focusing on concise rapid reporting of clinical studies and reviews in COPD. Special focus is given to the pathophysiological processes underlying the disease, intervention programs, patient focused education, and self management protocols.

\section{Dovepress}

This journal is indexed on PubMed Central, MedLine and CAS. The manuscript management system is completely online and includes a very quick and fair peer-review system, which is all easy to use. Visit http://www.dovepress.com/testimonials.php to read real quotes from published authors. 